\title{
Do experts make mistakes? A comparison of human and machine identification of dinoflagellates
}

\author{
Phil F. Culverhouse ${ }^{1, *}$, Robert Williams ${ }^{2}$, Beatriz Reguera ${ }^{3}$, Vincent Herry ${ }^{1}$, \\ Sonsoles González-Gil ${ }^{3}$ \\ ${ }^{1}$ Centre for Intelligent Systems, University of Plymouth, Plymouth PL4 8AA, United Kingdom \\ ${ }^{2}$ Plymouth Marine Laboratory, Prospect Place, The Hoe, Plymouth PL1 3DH, United Kingdom \\ ${ }^{3}$ Instituto Español de Oceanografía Apartado 1552, 36280 Vigo, Spain
}

\begin{abstract}
The authors present evidence of the difficulties facing human taxonomists/ecologists in identifying marine dinoflagellates. This is especially important for work on harmful algal blooms in marine aquaculture. It is shown that it is difficult for people to categorise specimens from species with significant morphological variation, perhaps with morphologies overlapping with those of other species. Trained personnel can be expected to achieve 67 to $83 \%$ self-consistency and $43 \%$ consensus between people in an expert taxonomic labelling task. Experts who are routinely engaged in particular discriminations can return accuracies in the range of 84 to $95 \%$. In general, neither human nor machine can be expected to give highly accurate or repeatable labelling of specimens. It is also shown that automation methods can perform as well as humans on these complex categorisations.
\end{abstract}

KEY WORDS: Classification - HAB dinoflagellates · Neural networks · Expert judgement • Categorisation · Marine ecology

\section{INTRODUCTION}

The categorisation or labelling of biological specimens is carried out manually by marine ecologists and expert taxonomists. Research to automate the task has been on-going for many years (Jefferies et al. 1980, 1984, Rolke \& Lenz 1984, Berman 1990, Berman et al. 1990, Hofstraat et al. 1994, Costas et al. 1995), relying on developments in pattern analysis, image processing, multi-spectral analysis and immunofluorescence. Although many systems have been shown to work in small-scale laboratory conditions with cultured populations, few have succeeded when applied to fieldcollected specimens. The reasons are diverse, but are principally due to severely degraded performance of the chosen processing algorithms in the presence of noise and natural morphological variability of the organisms. Even recently developed flow-cytometer systems (Dubelaar et al. 1989, Jonker et al. 1995) are limited in their utility by virtue of their powers of dis-

*Email: p.culverhouse@plymouth.ac.uk crimination with multispectral laser probes and their very limited sampling rates $\left(2.5 \mathrm{ml} \mathrm{h}^{-1}\right)$.

Recently, artificial neural networks (ANN), which are essentially new methods of noise-resilient and trainable pattern-matching algorithms, have offered increased reliability and robustness. Several programmes have shown the efficacy of systems based on these methods (Simpson et al. 1991, Boddy \& Morris 1993, Culverhouse et al. 1996, Davis et al. 1996, Toth \& Culverhouse 1999, Solow et al. 2001).

Statistical methods are also being developed by marine taxonomists to assist their understanding of species classification. These methods seek to categorise specimens according to morphological (Williams et al. 1994, McCall et al. 1996, Lassus et al. 1998, Truquet et al. 1996) and genetic (Bucklin \& Kann 1991, Bucklin et al. 1996, Hill et al. 2001) classification.

Progress in automatic categorisation is usually measured by percent correct label. Descriptions of confusions, which highlight incorrect attributions of label, 
are also common. Machine learning systems have a particular problem associated with their operation; that of being trained with wrongly labelled data. This is normally overcome by a validation process, whereby specimens to be used in the training processes are labelled by a committee of experts. Only specimens for which a high consensus of agreement is obtained are used for training, but this limits operational use of such devices to non-expert discriminations of taxa, rather than species. If we are to push the limits of machine taxonomy, we need to operate in this 'grey area' where high intraspecific morphological variance is the norm.

The validation process is made more complex by morphological variation exhibited by the specimens due to environmental and genetic pressure. Consensus between experts is then difficult to obtain. It has been presumed in the past that this validation process works well where there are many experts and where there is general agreement between experts on the taxonomy of the species being sampled.

Existing dogma in marine ecology maintains that marine scientists engaged in routine labelling of specimens in net and bottle samples are nearly 100\% accurate in their assays. Anecdotal evidence from informal studies contradicts this perfect performance, suggesting that they may suffer from systematic biases that significantly degrade their performance.

The motivation for this study was to assess human performance in a difficult categorisation task and to compare their accuracy against the Dinoflagellate Categorisation by Artificial Neural Network (DiCANN) machine learning system, which was developed under European Union MAST2 ct92-0015 and MAST3 ct98-0188 contracts.

Evidence is presented in this paper that confirms this degraded performance, and that experts are more error-prone in their judgements than assumed.

\section{METHODS}

Human performance in identifying and sorting organisms under microscopes is affected by several psychological factors: (1) the human short-term memory limit of 5 to 9 items stored; (2) fatigue and boredom; (3) recency effects whereby a new classification is biased toward those in the set of most recently used labels; (4) positivity bias, whereby labelling a specimen is biased by one's expectations of the species present in the sample (Evans 1987). Human experts also make up their own rules for categorisation tasks (Sokal 1974). Humans are not good long-term visual categorisation instruments. These biases routinely affect the quality of taxonomic surveys that underpin marine ecology. There is also a tacit assumption that a 'gold standard' of specimen-labelling exists (as used in Solow et al. 2001 to simplify assessment of machine methods). Taxonomists set the gold standards by careful inspection of individual specimens. These standards must always be interpreted for human or machine routine HAB (harmful algal bloom) monitoring and plankton surveys, in which a high throughput of samples is an issue. In these circumstances 100\% accurate labelling is not possible, because of human error which is compounded by morphological variation in the target species adding confusing information to the task.

The species used in the present study were members of the dinoflagellates. The dinoflagellates are an interesting group, in that many species have polymorphic life cycles with motile vegetative stages, which in some species exhibit considerable morphological variability, as well as a resting or 'cyst' stage. This variability in the vegetative stage can cause debate in their classification (examples in Figs. 1 \& 2). Therefore, categorisation of HAB dinoflagellates, acknowledged as difficult taxa, provides a test for both automation tools and for human taxonomists.

Extreme morphological variation within species creates deep problems for a classification based on visual descriptions. An example of such variation among the species of interest is Dinophysis acuminata, which is found frequently and extensively in European waters, and is the main agent of diarrhetic shellfish poisoning (DSP) episodes in the Galician riàs and waters of other European Union countries (Bravo et al. 1995a). It shows a high degree of morphological variability between geographical regions and seasons, and its taxonomic position is in conflict with a close species, D. sacculus, which is of much lower toxicity (Bravo et al. 1995b, Reguera et al. 1997).

Images of fixed specimens (Lugol and formalin) used in the study were digitised to a computer using monochrome video or digital cameras connected to Zeiss Axiovert microscopes with 1:1 aspect ratios for sampling and digitising (see Figs. 1 \& 2 for examples). These were clipped to approximately $256 \times 256$ pixels, ensuring only 1 specimen per image. The experiment was designed to compare human and machine labelling performance in routine HAB monitoring and ecological surveys, where visual inspection is the norm for rapid inspection and identification of large numbers of specimens in a sample. The specimens were drawn from field-collected samples, which exhibited naturally-occurring morphological variability.

Sixteen volunteer study subjects (marine ecologists and HAB monitoring specialists), drawn from across the European Union, were given access to the image data set via the Internet. An image drawn from the data set was displayed and the subjects were asked to 
give each specimen a label, selected from a drop-down menu of labels. Their labels were recorded in a database for performance analysis. Initial labelling of specimens in the data set was carried out using the 2-expert protocol established in an earlier 'MAST'-funded programme and reported in Culverhouse et al. (1996). Specimens used in the study were given species labels by one of the authors (S. Gonzales-Gil); these were subsequently validated by an independent expert in the taxonomy of these species and their morphotypes (B. Reguera). The task was graded as 'hard' by this validator for the following reasons: (1) Several images corresponded to Dinophysis skagii, which is a small form of $D$. acuminata. These could be acceptably labelled as either $D$. acuminata or 'not any of these'. (2) There were clearly several images of intermediate forms of $D$. tripos (lacking the dorsal process) in the data set. A specialist on small-intermediate cell formation would not make a mistake, but probably all our experts would call them D. caudata. (3) Uncertainty was created by the fact that $D$. acuminata images were taken at higher magnification $(630 \times)$ than the others. There are certain features (straight ventral margin, etc.) that distinguish $D$. acuminata from $D$. fortii, but in a quick scan people would base their choice largely on a combination of these features, plus size.

The machine learning system, DiCANN, was trained on 128 of the 310 -sample image data set and tested on the remaining 182 samples. All images in the data set were subjected to morphometric analysis to establish species category for each.

DiCANN applies the coarse-coded channel method for image analysis (Ellis et al. 1997) (Fig. 3). Specimen images are processed at low resolution through several complementary channels. The resulting numeric descriptor is fed into an automatic categoriser for training and testing.

An early prototype has been trained on 100 specimens per species drawn from an image database of over 5000 field-collected dinoflagellates. Best performance on test data drawn from the same database was $83 \%$ across 23 species of field-collected dinoflagellate
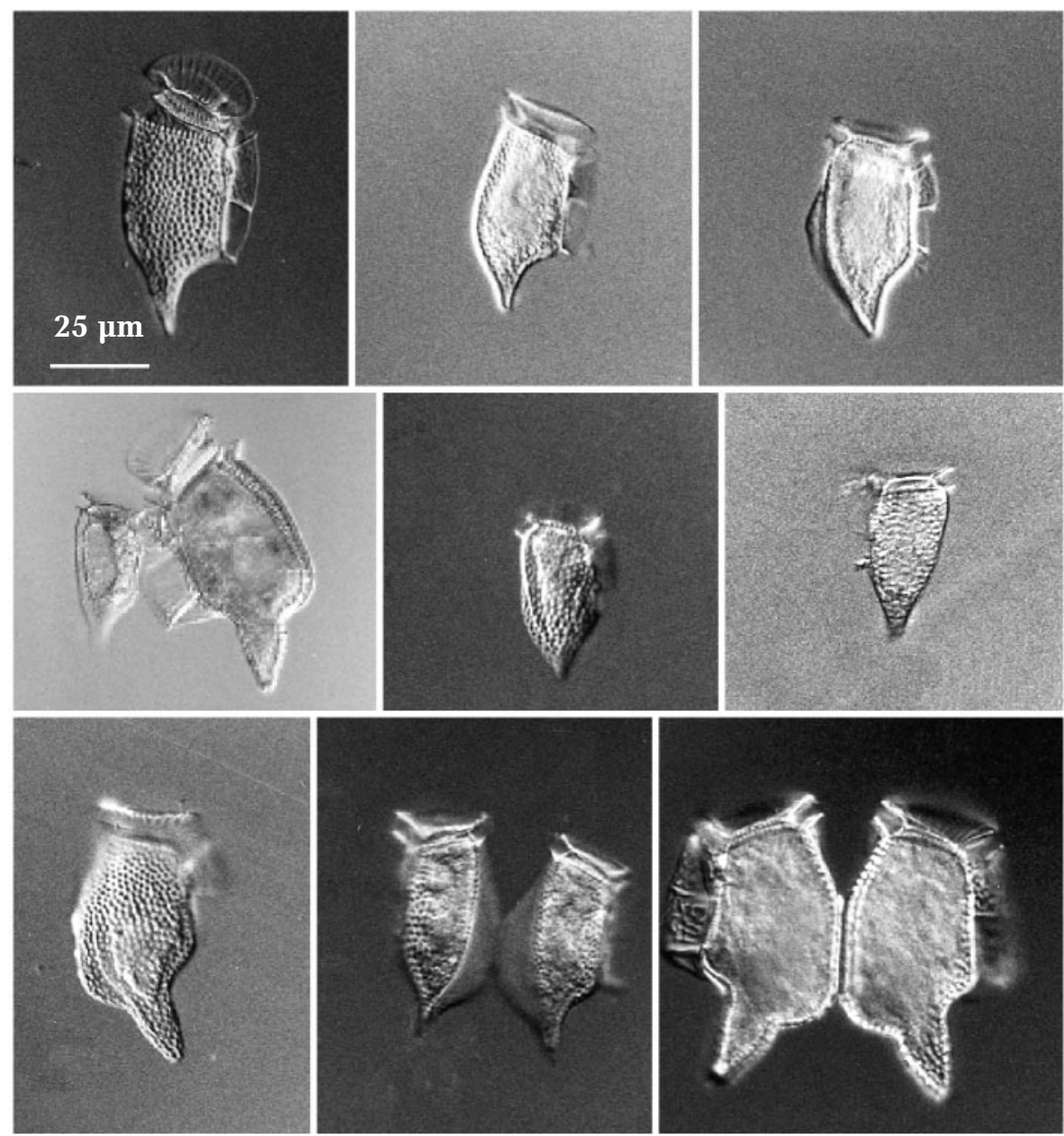

Fig. 1. Dinophysis caudata. Images showing polymorphism 
(Culverhouse et al. 1996). The DiCANN processing is invariant to specimen rotation and translation in the field of view. It is also partially invariant to scale, allowing up to $10 \%$ variation in specimen size. DiCANN recognises 3D objects from different viewpoints through training on a range of views which are then interpolated by the training process (Toth \& Culverhouse 1999). DiCANN may not succeed at recognising an object from an unusual view angle if it is easily confused with another object. In this manner DiCANN is no different from a human taxonomist.

\section{RESULTS AND DISCUSSION}

The 16 experts reviewed and labelled the images over a 2 wk period from computers connected to the Internet in their work places. Analysis of their performance is shown in Table 1 . Their overall performance in this difficult task was only $72 \%$. A wide variation in species recognition was noted, with Dinophysis caudata and $D$. rotundata proving easily discriminable from other species at $>90 \%$ performance. $D$. tripos followed with $86 \%$ accuracy, being mostly confused with
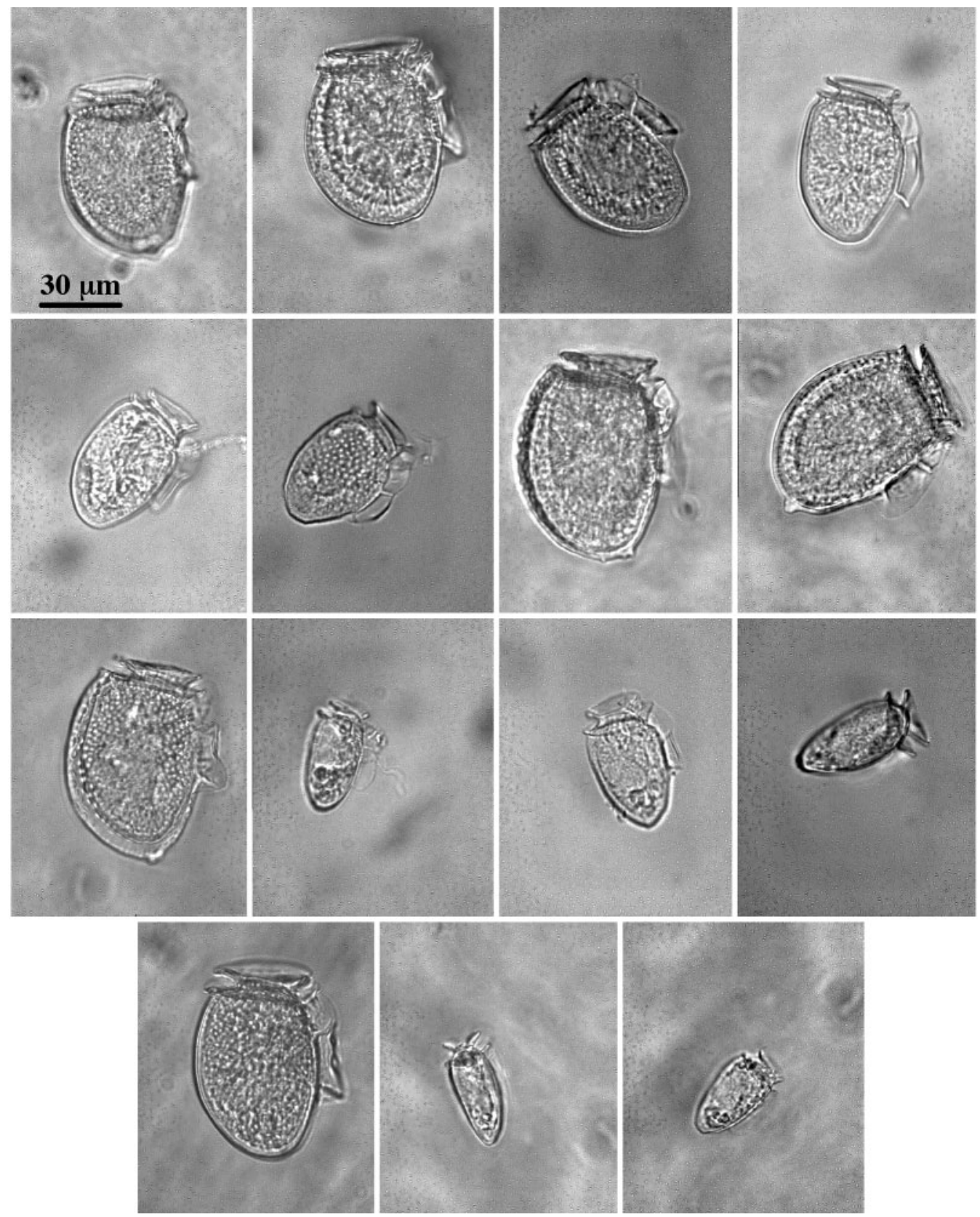

Fig. 2. Dinophysis acuminata. Images showing morphological changes in incubated cells 


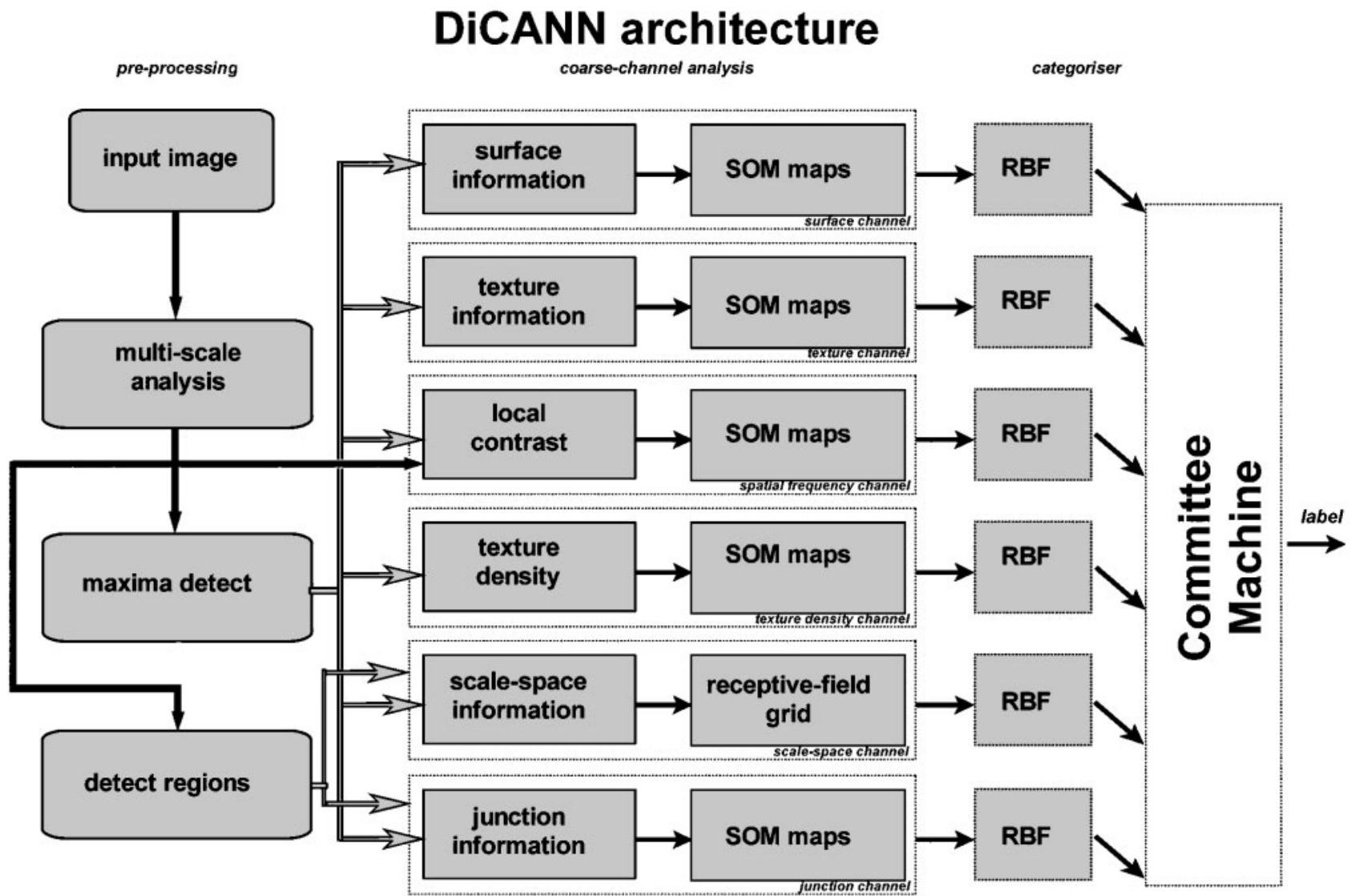

Fig. 3. Schematic diagram of DiCANN

D. caudata. D. sacculus images were only $65 \%$ correctly labelled, with many difficult specimens being labelled as 'no idea' or D. acuta. Finally, D. fortii and D. acuminata proved especially difficult for the subjects to label, with 50 and $38 \%$ correct labels respectively for these species.
The experts' primary confusion accords with the earlier comments of B. Reguera, i.e. that Dinophysis acuminata can be confused with $D$. sacculus, especially when the normally observed differences in scale due to specimen magnification are removed ( $D$. acuminata is normally resolved at $630 \times$, the remaining species at

Table 1. Dinophysis spp. Confusion table for 6 species identified by human experts

\begin{tabular}{|c|c|c|c|c|c|c|c|}
\hline & D. fortii & D. rotundata & D. acuminata & D. caudata & D. tripos & D. sacculus & D. acuta \\
\hline D. fortii & 762 & 9 & 79 & 1 & 2 & 6 & \\
\hline D. rotundata & & 916 & 29 & 1 & 1 & & \\
\hline D. acuminata & 225 & 6 & 345 & 5 & 4 & 11 & \\
\hline D. caudala & 21 & 2 & 15 & 898 & 38 & & \\
\hline D. tripos & 2 & & & 32 & 502 & 1 & \\
\hline D. sacculus & 316 & 2 & 166 & 1 & 4 & 186 & \\
\hline D. acuta & 162 & 7 & 226 & 2 & 2 & 25 & None in sample \\
\hline None of these & 1 & 13 & 12 & 2 & 4 & 7 & \\
\hline No idea & 10 & 5 & 27 & 4 & 9 & 48 & \\
\hline Response & 1499 & 960 & 899 & 9446 & 566 & 284 & \\
\hline$\%$ correct & $50.83 \%$ & $95.42 \%$ & $38.38 \%$ & $94.93 \%$ & $88.69 \%$ & $65.49 \%$ & \\
\hline \multicolumn{4}{|c|}{ Overall accuracy of subjects (\%) } & 72.29 & & & \\
\hline
\end{tabular}


Table 2. Dinophysis spp. Confusion table for 6 species identified from DiCANN categorisation data

\begin{tabular}{|c|c|c|c|c|c|c|c|}
\hline & D. fortii & D. rotundata & D. acuminata & D. caudata & D. tripos & D. sacculus & $\begin{array}{l}\text { Overall } \\
\text { accuray }\end{array}$ \\
\hline D. fortii & 35 & 2 & 4 & 4 & 0 & 0 & \\
\hline D. rotundata & 0 & 32 & 7 & 2 & 0 & 0 & \\
\hline D. acuminata & 12 & 0 & 12 & 11 & 0 & 0 & \\
\hline D. caudata & 3 & 1 & 5 & 23 & 4 & 0 & \\
\hline D. tripos & 0 & 0 & 0 & 1 & 15 & 0 & \\
\hline D. sacculus & 0 & 3 & 1 & 0 & 0 & 5 & \\
\hline Totals & 50 & 38 & 29 & 41 & 19 & 5 & 182 \\
\hline Label & $70.00 \%$ & $84.21 \%$ & $41.38 \%$ & $56.10 \%$ & $78.95 \%$ & $100.00 \%$ & $71.77 \%$ \\
\hline
\end{tabular}

$400 \times)$. However, this magnification confusion is constant for both human and DiCANN labelling and can thus be discounted as a performance issue.

On the same test data set, DiCANN returned a performance of $72 \%$ (Table 2).

It should be noted that the identification task for humans was limited, since normal viewing of these species is through a microscope, whereby the analyst controls the depth of field. This provides a greater level of detail than that provided by the fixed planes of focus monochrome images.

Human biases and prior expectations also influence the outcome of a labelling task. If the population of dinoflagellates in routine sea water samples does not normally contain Dinophysis acuta, then the expert ecologist will not be disposed to label rare occurrences of D. acuta correctly, perhaps resulting in mis-categorisation as (for example) $D$. fortii. It is clear from the human mistakes in this study, that biases influenced the decision-making processes when labelling a specimen. For example there was no $D$. acuta in the data set, yet a significant number of $D$. fortii were labelled as $D$. acuta by mistake, the bias arising from the presence of a $D$. acuta label in the selection menu.

Table 3 summarises the performances of humans and DiCANN across the species. It can be seen that there is broad agreement in the performances; however 2 exceptions are apparent: firstly Dinophysis caudata, which humans were able to identify with $94 \%$ accuracy but for which DiCANN could only achieve $56 \%$ accuracy; secondly D. sacculus, for which machine accuracy was $100 \%$ but human accuracy only $65 \%$.

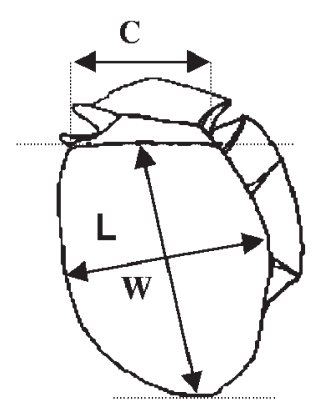

Fig. 4. Prototypical Dinophyceae specimen, showing the 3 morphological parameters used in the study. C: dorso-ventral width of the epitheca; L: maximum length of the hypotheca; W: dorso-ventral width of the hypotheca

Linear discrimination analysis (LDA) of standard morphological measurements of the specimens reflects the performance trends described above. Only 3 measurement parameters were used, as these were common across all species (Fig. 4). There is no evidence to suggest that the subjects used these parameters in their selection of label, and DiCANN uses a different set of features to arrive at its discriminations (essentially multi-channel shape and texture analysis). There is no apparent common mode of operation, yet the canonical discriminant function plot in Fig. 5 shows that several of the test species share very similar morphometric characteristics.

This suggests that confusion can arise in categorisation where, for example, specimens of Dinophysis caudata have morphological parameters overlapping with the main cluster of $D$. fortii specimens and $D$. acuminata. In fact, all 3 metrics of difficulty and confusion

Table 3. Dinophysis spp. Comparison of human and DiCANN categorising performance for 6 species

\begin{tabular}{|lccccccc|}
\hline Performance & D. fortii & D. rotundata & D. acuminata & D. caudata & D. tripos & D. sacculus & Overall \\
\hline Human & $50.83 \%$ & $95.42 \%$ & $38.38 \%$ & $94.93 \%$ & $88.69 \%$ & $65.49 \%$ & $72.29 \%$ \\
DiCANN & $70.00 \%$ & $84.21 \%$ & $41.38 \%$ & $56.10 \%$ & $78.95 \%$ & $100.00 \%$ & $71.77 \%$ \\
\hline
\end{tabular}




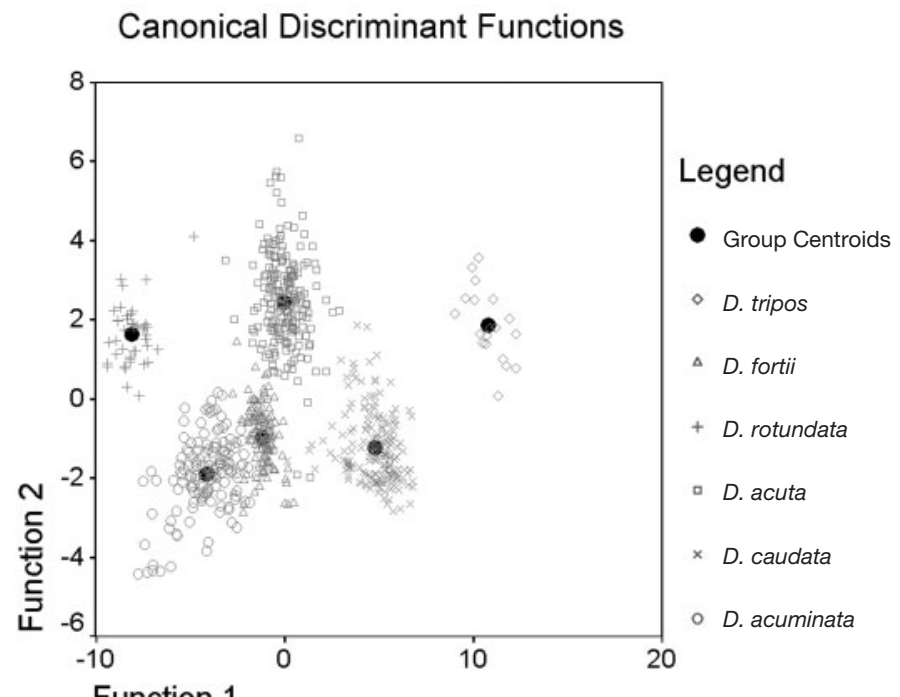

Function 1

Fig. 5. Dinophysis spp. Linear discriminant analysis plot of morphological variation across 6 test species

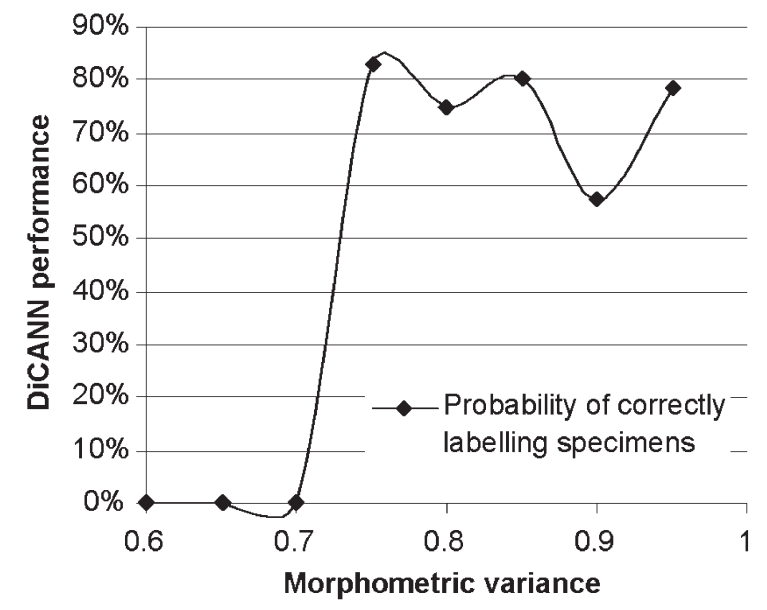

Fig. 6. Dinophysis spp. Plot of relationship between DiCANN performance and morphological variance of training set species (human, LDA and DiCANN) indicate that the task of labelling the Dinophysis species was difficult. A comparison of these 3 metrics suggests that mistakes made by both human and DiCANN were due to the overlapping morphological characteristics of the specimens in the data set. Fig. 6 shows the relationship between DiCANN performance and intraspecific variance in the morphology. It reveals that DiCANN is able to operate with up to $25 \%$ variance of morphology within a species before its performance degrades below $75 \%$ on average.

Expert judgement is not $100 \%$ accurate. In published studies by the authors (Simpson et al. 1992, 1993, Culverhouse et al. 1994, 1996) it has been shown that an individual's accuracy and repeatability must be assessed in comparison to his or her peers, producing a consistency score. Agreement between experts is of paramount importance in providing robust analysis of samples. Table 4 highlights the limitations of human categorisers and compares their performance to machine learning systems developed by the authors in these earlier studies. It is interesting that the $23 \mathrm{spp}$. dinoflagellate task showed the best agreement between categorisation by the automatic methods (83\%) developed by the authors and that by a panel of experts (86\%) (see Culverhouse et al. 1996).

\section{CONCLUSIONS}

This study has highlighted the difficulties facing human taxonomists, and has shown that automation methods can perform complex categorisations as well as humans. However, it is clear that human performance of $<100 \%$ accuracy must be acknowledged as normal in scientific enquiry. It must also be accepted that machine learning performance is likely to be similar to human performance, with the exception that with careful training machine systems may not suffer from the same systematic biases as humans. Finally, it

Table 4. Dinophysis spp. Summary of human performances in categorisation of various species. na: not applicable

\begin{tabular}{|c|c|c|c|}
\hline Categorisation task & $\begin{array}{l}\text { Self-consistency within } \\
\text { panel individuals }\end{array}$ & $\begin{array}{l}\text { Panel-consistency } \\
\text { across individuals }\end{array}$ & Machine performance \\
\hline $\begin{array}{l}\text { Ceratium longipes }+ \\
\text { C. arcticum }\end{array}$ & $\begin{array}{l}\text { Competent expert: 94-99\% } \\
\text { 'Book' expert } 67-83 \%\end{array}$ & 95 to $43 \%$ across 8 experts & $99 \%$ \\
\hline 5 species Tintinnidae & na & $91 \%$ consistent across 6 experts & $87 \%$ \\
\hline \multicolumn{4}{|l|}{3 species fish larvae } \\
\hline 5-9 spp. dinoflagellates & na & $91-95 \%$ consistent across 6 experts & $\begin{array}{l}67 \% \text { (low figure due to con- } \\
\text { fusion between C. longipes } \\
+ \text { C. arcticum) }\end{array}$ \\
\hline 23 spp. dinoflagellates & na & $83-86 \%$ consistent across 6 experts & $83 \%$ \\
\hline
\end{tabular}


must be recognised that it is difficult to categorise specimens from species with significant interspecific morphological variation, perhaps with morphologies overlapping with those of other species. Our studies (Table 4) indicate that trained personnel can be expected to achieve 67 to $83 \%$ self-consistency in an expert taxonomic labelling task, a figure which drops to $43 \%$ when compared to labelling by others. Experts who are routinely engaged in particular discriminations can become highly self- and mutually-consistent, for example within a HAB monitoring laboratory, where consensus is achieved through regular dialogue and debate. Our study reveals that these people can return accuracies in the range of 84 to $95 \%$. In general, neither human nor machine can be expected to give highly accurate or repeatable labelling of specimens in tasks that contain large amounts of noise. In the context of specimen labelling, morphological variance can be interpreted as noise: the higher the variance in visual characteristics of natural objects, the harder it is to recognise them.

The diversity of the natural world has confounded rule-based and numerical techniques for pattern analysis. Taxonomic key tables have limited value in automatic systems, but continue to provide the standards for taxonomy. The reason is perhaps that the expert taxonomists, who are the target users for these keys, must still apply considerable skill in identifying biological specimens. These skills, however, are not perfect, and performances can be lower than expected from trained professional ecologists. Book experts (as opposed to those with field expertise) are not self-consistent, nor consistent with other experts. Specialists who have honed their decision-making skills through repeated practice can be up to $95 \%$ self-consistent and are also able to form high level consensus of opinion with other experts (84\% in this study), even for repeated tasks. But both types of expert still suffer from cognitive biases that degrade their performance over time. The task of labelling biological specimens is error-prone and should be acknowledged as such. This is contrary to the dogma existing at the present time, and impacts on how machine performance is viewed.

Finally, recall that the validator graded the task as 'hard'. Under these conditions, it might be expected that a wider view on consensus be sought. In effect, this experiment is a detailed review of the formation of that consensus. It is clear that even experts cannot totally agree. These results provide information on the nature of consensus for 'hard' categorisation tasks in the future. Zingone (1996) comments 'it seems the best results in identification of algal species may be obtained by combining different methods: observational (including swimming patterns), morphometrical, fluorometrical and others)'. The message is clear for taxon- omists: use all available methods to ensure robust categorisation and species delineation. These are timeconsuming to apply at present. Thus, for routine HAB monitoring and ecology surveying whereby large volumes of plankton must be quickly labelled, acceptable levels of human (or machine) error must be assessed and reported as part of laboratory experiment practices.

Acknowledgements. We wish to thank all the participants in the labelling trials reported in this paper. We also acknowledge the support of the European Union through grant MAS3-ct98-0188.

\section{LITERATURE CITED}

Berman MS (1990) Application of image analysis in demographic studies of marine zooplankton. In: Sherman K, Gold B, Alexander L (eds) Large marine ecosystems: patterns, processes and yields. AAAS Press, Washington, DC, p 122-131

Berman MS, Katsinis C, Jeffries HP, Lambert RM (1990) Image analysis techniques for the identification and measurement of marine zooplankton. (Abstr.) EOS Trans Am Geophys Union 71:94

Boddy L, Morris CW (1993) Analysis of flow cytometry dataa neural network approach. Comput Microbiol 5:17-22

Bravo I, Deladago M, Fraga S, Honsell G, Lassus P, Montresor M, Sampayo MA (1995a) The Dinophysis genus: toxicity and species definition in Europe. In: Lassus P, Arzul G, Erard-le Denn E, Gentien P, Marcaillou-le Baut (eds) Toxic marine phytoplankton. Lavoisier Publishing, Paris, p 843-845

Bravo I, Reguera B, Fraga S (1995b) Description of different morphotypes of $D$. acuminata complex in the Galician Riás Bajas in 1991. In: Lassus P, Arzul G, Erard-le Denn E, Gentien P, Marcaillou-le Baut (eds) Toxic marine phytoplankton. Lavoisier Publishing, Paris, p 21-26

Bucklin A, Kann L (1991) Mitochondrial-DNA variation of copepods-markers of species identity and population differentiation in Calanus. Biol Bull (Woods Hole) 181: 357-357

Bucklin A, Sundt RC, Dahle G (1996) The population genetics of Calanus finmarchicus in the North Atlantic. Ophelia 44: $29-45$

Costas E, San Andrés MI, Gonzálas-Gil S, Aguilera A, LópezRodas V (1995) A procedure to estimate okadaic acid in whole dinoflagellate cells using immunological techniques. J Appl Phycol 7:407-411

Culverhouse PF, Ellis RE, Simpson R, Williams R, Pierce RW, Turner JT (1994) Categorisation of 5 species of Cymatocylis (Tintinidae) by artificial neural network. Mar Ecol Prog Ser 107:273-280

Culverhouse PF, Simpson RG, Ellis R, Lindley JA and 8 others (1996) Automatic categorisation of 23 species of dinoflagellate by artificial neural network. Mar Ecol Prog Ser 139: 281-287

Davis CS, Gallagher SM, Marra M, Stewart WK (1996) Rapid visualization of plankton abundance and taxonomic composition using the video plankton recorder. Deep-Sea Res Part II Top Stud Oceanogr 43:1947-1970

Dubelaar GBJ, Groenewegen AC, Stokdijk W, van den Engh GJ, Visser JWM (1989) The optical plankton analyser 
(OPA): a flowcytometer for plankton analysis, II: specifications. Cytometry 10:529-539

Ellis RE, Simpson RG, Culverhouse PF, Parisini T (1997) Committees, collectives and individuals: expert visual classification by neural network. Neural Comput Applic 5:99-105

Evans JStBT (1987) Bias in human reasoning: causes and consequences. Laurence Erlbuam, Hove, UK

Hill RS, Allen LD, Bucklin A (2001) Multiplexed speciesspecific PCR protocol to discriminate four N. Atlantic Calanus species, with an mtCOI gene tree for ten Calanus species. Mar Biol 139:279-287

Hofstraat JW, van Zeijl WJM, de Vreeze MEJ, Peeters JCH, Peperzak L, Colijn F, Rademaker TWM (1994) Phytoplankton monitoring by flow cytometry. J Plankton Res 16: 1197-1224

Jeffries HP, Sherman K, Maurer R, Katsinis C (1980) Computer-processing of zooplankton samples. In: Estuarine perspectives. Academic Press, New York, p 303-316

Jeffries HP, Berman MS, Poularikas AD, Katsinis C, Melas I, Sherman K, Bivins L (1984) Automated sizing, counting and identification of zooplankton by pattern recognition. Mar Biol 78:329-334

Jonker RR, Meulemans J, Dubelaar GBJ, Wilkins MF, Ringelberg J (1995) Flow cytometry: a powerful tool in analysis of biomass distributions in phytoplankton. Water Sci Technol 32:177-182

Lassus P, Seguel M, Truquet P (1998) Morphological study of atypical Dinophysis acuta Ehrenberg from Chilean coastal waters by a digital pattern-recognition system. Bot Mar 41:435-441

McCall H, Bravo I, Lindley JA, Reguera B (1996) Phytoplankton recognition using parametric discriminants. J Plankton Res 18(3):393-410

Reguera B, Bravo I, McCall H, Reyero MI (1998) Phased cell division and other biological observations in field populations of Dinophysis during cell cycle studies. In: Yasumoto T, Oshima Y, Fukuyo Y (eds) Harmful and toxic algal

Editorial responsibility: Kenneth Sherman (Contributing Editor), Narragansett, Rhode Island, USA blooms. Intergovernmental Oceanographic Commission of UNESCO Publishers, Sendai, p 257-260

Rolke M, Lenz J (1984) Size structure analysis of zooplankton samples by means of an automated image analyzing system. J Plankon Res 6:637-645

Simpson R, Culverhouse PF, Ellis R, Williams R (1991) Classification of Euceratium Gran. in neural networks. IEEE International Conference on Neural Networks in Ocean Engineering, Washington, DC, USA, August 1991. IEEE, Piscataway, NJ, p 223-230

Simpson R, Williams R, Ellis R, Culverhouse PF (1992) Biological pattern recognition by neural networks. Mar Ecol Prog Ser 79:303-308

Simpson R, Williams R, Ellis R, Culverhouse PF (1993) Classification of Dinophyceae by artificial neural networks. In: Smayda TJ, Shimizu Y (eds) Toxic phytoplankton blooms in the sea. Elsevier Science, New York, p 183-190

Sokal RR (1974) Classification: purposes, principles, progress, prospects. Science 185:1115-1123

Solow A, Davis C, Hu Q (2001) Estimating the taxonomic composition of a sample when individuals are classified with error. Mar Ecol Prog Ser 216:309-311

Toth L, Culverhouse PF (1999) Three-dimensional object categorisation from static $2 \mathrm{D}$ views using multiple coarse channels. Image Vision Computing 17:845-858

Truquet P, Lassus P, Honsell G, LeDean L (1996) Application of a digital pattern recognition system to Dinophysis acuminata and $D$. sacculus complexes. Aquat Living Resour 9:273-279

Williams R, McCall H, Pierce RW, Turner JT (1994) Speciation of the tintinnid genus Cymatocylis by morphometric analysis of the lorica. Mar Ecol Prog Ser 107:263-272

Zingone A (1996) Session 1a: The requirements of taxonomy. In: Culverhouse P, Williams B, Reguera B (eds) Workshop on automatic categorisation of marine biological material for ecosystem research and monitoring. University of Plymouth, Plymouth, UK

Submitted: January 15, 2002; Accepted: August 12, 2002 Proofs received from author(s): January 16, 2003 